\title{
STUDI IDENTIFIKASI KERUSAKAN WILAYAH PESISIR DI KOTA BENGKULU
}

\author{
Zamdial, Dede Hartono, Deddy Bakhtiar, Eko Nofridiansyah \\ Program Studi IImu Kelautan Universitas Bengkulu \\ E-mail : zamdial_et@yahoo.co.id
}

Received March 2018, Accepted April 2018

\begin{abstract}
ABSTRAK
Kota Bengkulu adalah ibukota dari Provinsi Bengkulu yang mempunyai wilayah pesisir dengan panjang garis pantai hanya $\pm 17,22 \mathrm{~km}$. Wilayah pesisir Kota Bengkulu memanjang dari Sungai Hitam di Kecamatan Muara Bangkahulu hingga Pulau Baai di Kecamatan Kampung Melayu. Kondisi wilayah pesisir Kota Bengkulu di beberapa tempat juga sudah mengalami degradasi, baik yang disebabkan oleh dinamika alam maupun karena pengaruh dari intervensi manusia. Penelitian ini bertujuan untuk mengindentifikasi kerusakan yang terjadi disepanjang wilayah pesisir Kota Bengkulu, Provinsi Bengkulu dan memetakan lokasi wilayah pesisir yang mengalamai kerusakan. Penelitian ini dilakukan pada bulan Oktober 2014. Penelitian ini dilakukan dengan metode survei. Kegiatan penelitian ini meliputi observasi lapang, wawancara dan pengambilan dokumentasi kerusakan yang terjadi sepanjang wilayah pesisir Kota Bengkulu. Analisis data untuk identifikasi kerusakan wilayah pesisir dilakukan secara statistik deskriptif. Hasil perhitungan Indeks Kerentanan Pantai (IKP), menunjukkan bahwa ada 14 lokasi kerusakan wilayah pesisir yang ditemukan di Kota Bengkulu, dengan nilai IKP secara berturut-turut yaitu Pantai Pondok Besi $(8,9)$; Pantai Jembatan Sungai Bangkahulu $(12,6)$; Pantai Pasar Bengkulu (12,6); Pantai Teluk Sepang (13,4); Pantai Sungai Hitam (17,9); Pantai Muara Sungai Bangkahulu (17,9); Pantai Jakat (17,9); Pantai Malabero (17,9); Pantai Sumur Melelh $(17,9)$; Pantai Samudera Ujung (19,0); Pantai Panjang (19,6); Pantai Sumber Jaya $(26,8)$; Muara Lempuing $(28,3)$ dan pantai Pasir Putih $(34,6)$. Secara umum wilayah pesisir Kota Bengkulu sudah mengalami degradasi. Kerusakan wilayah pesisir paling parah ditunjukkan dengan Nilai IKP terbesar yaitu Pantai Pasir Putih $(34,6)$ dan kerusakan yang paling ringan dijumpai di Pantai Pondok Besi dengan Nilai IKP 8,9. Kerusakan wilayah pesisir di Kota Bengkulu dikarenakan faktor-faktor berikut, yaitu alih fungsi lahan, abrasi, dan pencemaran.
\end{abstract}

Kata Kunci : IKP, Kerusakan, Kota Bengkulu, Wilayah Pesisir 


\begin{abstract}
Bengkulu City is the capital of Bengkulu Province which has coastal area with long coastline only $\pm 17.22 \mathrm{~km}$. The coastal area of Bengkulu City extends from the Sungai Hitam in Muara Bangkahulu District to Pulau Baai in Kampung Melayu District. The condition of the coastal area of Bengkulu City in some places have been also struck degradation, both caused by the dynamics of nature and because of the influence of human intervention. This study aims to identify the damage that occurred along the coastal areas of Bengkulu City, Bengkulu Province and mapped the location of coastal areas that have been damage. This study was conducted in October 2014. This research was conducted by survey method. The research activities include field observation, interviews and documentation of damage occurring along coastal areas of Bengkulu City. Data analysis for the identification of coastal area damage was done by descriptively statistic. The calculation result of Coastal Vulnerability Index (CVI), shows that there are 14 locations of coastal areas damage that found in Bengkulu City, with the value of CVI respectively that are Pantai Pondok Besi (8,9); Pantai Jembatan Sungai Bangkahulu (12,6); Pantai Pasar Bengkulu (12,6); Pantai Teluk Sepang (13,4); Pantai Sungai Hitam (17,9); Pantai Muara Sungai Bangkahulu (17,9); Pantai Jakat (17,9); Pantai Malabero (17,9); Pantai Sumur Melelh (17,9); Pantai Samudera Ujung (19,0); Pantai Panjang (19,6); Pantai Sumber Jaya (26,8); Muara Lempuing $(28,3)$ and Pantai Pasir Putih $(34,6)$. In general, the coastal area of Bengkulu City have been degraded. The worst coastal areas damage was indicated by the largest CVI value of Pantai Pasir Putih (34.6) and the slightly damage was found in Pantai Pondok Besi with CVI value of 8.9. Damage to coastal areas in the City of Bengkulu due to the following factors, namely the convertion of land functions, abrasion, and pollution.
\end{abstract}

Keywords : CVI, Damage, Bengkulu City, Coastal Regions

\title{
PENDAHULUAN
}

Secara geografis wilayah Kota Bengkulu terletak antara $30^{\circ} 45^{\prime}-$ $30^{\circ} 59^{\prime}$ Lintang Selatan dan $102^{\circ} 14^{\prime}$ - 102 $22^{\circ}$ Bujur Timur dengan luas wilayah $539,3 \mathrm{~km}^{2}$ terdiri dari luas daratan $151,7 \mathrm{~km}^{2}$ dan luas laut 387,6 km2. Jika melihat letak Kota Bengkulu, maka daerah ini sebagian besar mempunyai lingkungan pesisir pantai yang terbuka dan berhadapan langsung dengan Samudera Hindia, sehingga gelombang dan arus berpengaruh besar terhadap kondisi wilayah pesisir.

Secara administratif Kota Bengkulu terdiri dari 9 wilayah kecamatan (Bappeda Kota Bengkulu, 2013). Berdasarkan kriteria wilayah kecamatan yang memiliki ekosistem pesisir atau berbatasan langsung dengan laut, maka di Kota Bengkulu. terdapat 7 Kecamatan pesisir, yaitu Kecamatan Muara Bangkahulu, Kecamatan Sungai Serut, Kecamatan Teluk Segara, Kecamatan Ratu Samban, Kecamatan Ratu Agung, Kecamatan Gading 66 
Cempaka dan Kecamatan Kampung Melayu (Fauzi, et al., 2009 dan BPS Kota Bengkulu, 2014).

Sebagian besar wilayah Kota Bengkulu boleh dikatakan bersentuhan dengan wilayah pesisir. Dengan demikian, kelangsungan hidup sebagian masyarakat dan keberlanjutan pembangunan (sustainability development) Kota Bengkulu juga sangat dipengaruhi oleh kelestarian wilayah pesisir tersebut. Wilayah pesisir memegang peranan penting dalam pembangunan masyarakat dan pembangunan daerah. Sebagaimana yang dijelaskan oleh Adisasmita (2008), daerah pesisir pantai mempunyai peranan yang penting dalam perekonomian masyarakat dan pembangunan karena merupakan ruang yang menjembatani antara wilayah daratan dan wilayah perairan (laut). Departemen Kelautan dan Perikanan (2002) dalam Arianto et al (2013) juga menegaskan bahwa sumberdaya pesisir berperan penting dalam mendukung pembangunan ekonomi daerah dan nasional untuk meningkatkan penerimaan devisa negara, lapangan kerja, dan pendapatan penduduk.

Sebagai ibu kota Provinsi Bengkulu, wilayah pesisir Kota Bengkulu mendapat tekanan yang diperkirakan lebih besar karena berbagai kepentingan pembangunan, termasuk untuk pembangunan berbagai infrastrukutr. Eksploitasi terhadap wilayah pesisir terjadi secara cepat, sehingga terjadi ketidakseimbangan dari daya dukung yang ada di wilayah pesisir tersebut yang tentunya dapat berdampak pada kerusakan secara ekologis. Sudah dapat dilihat secara kasat mata, bahwa sepanjang wilayah pesisir Kota Bengkulu sudah terjadi fenomena abrasi, sedimentasi, hilangnya vegetasi wilayah pesisir dan terjadinya perubahan garis pantai.

Kegiatan penelitian tentang identifikasi kerusakan wilayah pesisir di Kota Bengkulu, seperti halnya dengan diberbagai wilayah pesisir lainnya, adalah sangat penting artinya dalam upaya mengantisipasi dan menghadapi serta menanggulangi berbagai bentuk kerusakan wilayah pesisir yang sudah terjadi dan kemungkinan akan terjadi.

Penelitian ini bertujuan untuk mengindentifikasi kerusakan yang terjadi disepanjang wilayah pesisir Kota Bengkulu, Provinsi Bengkulu dan sekaligus membuat peta lokasi wilayah pesisir yang sudah mengalamai kerusakan. Hasil dari penelitian ini diharapkan dapat menjadi data dan informasi bagi masyarakat, pemerintah dan pihak-pihak yang berkepentingan terhadap perencanaan, pemanfaatan dan pengelolaan wilayah pesisir di Kota Bengkulu.

\section{MATERI DAN METODE}

Penelitian identifikasi kerusakan wilayah pesisir di Kota Bengkulu, Provinsi Bengkulu ini dilakukan pada bulan Oktober 2014. Ruang lingkup wilayah penelitian adalah di sepanjang wilayah pesisir Kota Bengkulu Provinsi Bengkulu mulai dari Kecamatan Muara Bangkahulu hingga Kecamatan Selebar. Pada penelitian ini data primer dikumpulkan dengan metode observasi di lokasi penelitian dan wawancara dengan beberapa 
responden. Penetapan responden dilakukan dengan metode purposive sampling dan accidental sampling. Data sekunder dikumpulkan dari berbagai sumber referensi yang terkait dengan materi pembahasan hasil penelitian.

Kondisi kerusakan yang disurvei yaitu seluruh kerusakan di wilayah pesisir, yang dapat diamati dan diidentifikasi secara langsung di lapangan. Kegiatan survei lapang dimaksudkan untuk mengumpulkan semua data kerusakan di wilayah pesisir, yang selanjutnya akan diidentifikasi. Hasil yang diharapkan dari identifikasi ini adalah : (a) Jenis kerusakan yang terjadi disuatu lokasi di wilayah pesisir; (b) Faktor-faktor apa saja yang menajadi penyebab kerusakan di wilayah pesisir; (c) Dampak yang ditimbulkan karena kerusakan yang terjadi di wilayah pesisir; (d) Alternatif penanggulangan kerusakan yang terjadi diwilayah pesisir; dan (e) Titik koordinat lokasi terjadinya kerusakan di wilayah pesisir.

Adapun peralatan yang digunakan dalam kegiatan penelitian ini adalah alat tulis, kamera, GPS (Global Positioning System), Clino Meter, Rol Meter, kuisioner, computer (Laptop) dan Software ArcGIS 9.2.

Data penelitian yang dikumpulkan di lapangan dianalisis dengan metode statistik deskriptif. Metode statistik deskriptif adalah Statistika deskriptif adalah metode statistika yang digunakan untuk menggambarkan atau mendeskripsikan data yang telah dikumpulkan menjadi sebuah informasi (Purwanto, 2012). Menurut Suparmi (2014), statistika deskriptif adalah bagian dari statistika yang membahas tentang cara pengumpulan data, pengolahan data, penyajian data, penentuan nilai-nilai statistika, dan pembuatan gambar mengenai sesuatu. Setelah dikumpulkan, data dapat disajikan dalam bentuk yang lebih mudah dipahami dan dibaca agar dapat memberikan gambaran tentang suatu peristiwa atau suatu keadaan.

Langkah berikutnya, berdasarkan data kerusakan wilayah pesisir yang telah dikumpulkan, akan dihitung Nilai Indeks Kerentanan Pantai (IKP) sepanjang wilayah pesisir Kota Bengkulu, Provinsi Bengkulu. Nilai Indeks Kerentanan Pantai selanjutnya dipakai guna menentukan lokasi yang mengalami kerusakan cukup tinggi dan memiliki resiko kerusakan yang besar apabila tidak segera ditangani. Nilai Indeks Kerentanan Pantai (IKP) dihitung dengan rumus dari Boruff et al (2005) :

$$
\text { IKP }=\sqrt{\frac{\text { Perkalian Bobot Semua Variabel }}{\text { Jumlah Variabel }}}
$$

Hasil perhitungan IKP akan dibandingkan dengan nilai standar tingkat kerentanan pantai wilayah pesisir yaitu sebagai berikut :

\begin{tabular}{|c|c|c|c|c|}
\hline IKP & $\mathbf{0 - 2 5}$ & $\mathbf{2 5 - 5 0}$ & $\mathbf{5 0 - 7 5}$ & $\mathbf{7 5 - 1 0 0}$ \\
\hline KERENTANAN & Rendah & Sedang & Tinggi & Sangat Tinggi \\
\hline
\end{tabular}


Untuk menghitung Nilai IKP, digunakan 8 variabel yaitu : Perubahan Garis Pantai (PP) berdasakran hasil wawancara, Pengamatan Visual Kerusakan (K), Panjang Kerusakan (PK), Lebar Kerusakan(LK), Lebar Sabuk Hijau (SH), Litologi Pantai (L), Penggunaan Lahan (PL), dan Kemiringan Pantai $(\beta)$. Menurut Jensent et al (1993) dan Noronha et al, (2003) dalam Boruff et al (2005).

Untuk mendapatkan nilai bobot dari masing-masing variabel di setiap lokasi kerusakan, maka digunakan ketentuan pembobotan (Tabel 1). Pembobotan variabel fisik didapat dengan membagi nilai variabel menjadi 5 (lima) tingkatan, dari yang paling ringan sampai yang paling berat kerusakannya (Boruff et al., 2005 dan DKP, 2004 dalam Wahyudi et al. (2009).

Tabel. 1. Ketentuan Pembobotan masing-masing variabel IKP

\begin{tabular}{|c|c|c|c|c|c|c|}
\hline \multirow[t]{2}{*}{ No } & \multirow[t]{2}{*}{ Variabel } & \multicolumn{5}{|l|}{ Bobot } \\
\hline & & 1 & 2 & 3 & 4 & 5 \\
\hline 1 & $\begin{array}{l}\text { Perubahan } \\
\text { Garis pantai } \\
\text { (PP) (Dari } \\
\text { hasil } \\
\text { Wawancara) }\end{array}$ & $0 \mathrm{~m} / \mathrm{th}$ & $\begin{array}{rr}(0-1) & m / t \\
h & \end{array}$ & $(1-5) \mathrm{m} / \mathrm{th}$ & $\begin{array}{l}(5-10) \\
\mathrm{m} / \mathrm{th}\end{array}$ & $\begin{array}{ll}> & 10 \\
\mathrm{~m} / \mathrm{th} & \end{array}$ \\
\hline 2 & $\begin{array}{l}\text { Pengamatan } \\
\text { Visual } \\
\text { Keruskan (K) }\end{array}$ & $\begin{array}{l}\text { Terlihat } \\
\text { Gejala } \\
\text { gerusan }\end{array}$ & $\begin{array}{l}\text { Terlihat } \\
\text { gerusan } \\
\text { tapi } \\
\text { masih } \\
\text { stabil }\end{array}$ & $\begin{array}{l}\text { Terjadi } \\
\text { gerusan } \\
\text { dan akan } \\
\text { terjadi } \\
\text { runtuhan }\end{array}$ & $\begin{array}{l}\text { Terjadi } \\
\text { gerusan } \\
\text { dan } \\
\text { runtuhan } \\
\text { tetapi } \\
\text { belum } \\
\text { membah } \\
\text { ayakan } \\
\text { sarana/pr } \\
\text { asarana }\end{array}$ & $\begin{array}{l}\text { Terjadi } \\
\text { gerusan } \\
\text { dan } \\
\text { rutuhan } \\
\text { dan } \\
\text { memba } \\
\text { hayakan } \\
\text { sarana/ } \\
\text { prasara } \\
\text { na }\end{array}$ \\
\hline 3 & $\begin{array}{l}\text { Panjang } \\
\text { keruskan } \\
(\mathrm{PK})\end{array}$ & $<0,5 \mathrm{~m}$ & $0,5-2 \mathrm{~km}$ & $2-5 \mathrm{~km}$ & $5-10 \mathrm{~km}$ & $>10 \mathrm{~km}$ \\
\hline 4 & $\begin{array}{l}\text { Lebar } \\
\text { Kerusakan } \\
\text { (LK) }\end{array}$ & $0 \mathrm{~m}$ & $1-10 \mathrm{~m}$ & 10- $50 \mathrm{~m}$ & $50-100 \mathrm{~m}$ & $>100 \mathrm{~m}$ \\
\hline 5 & $\begin{array}{l}\text { Lebar sabuk } \\
\text { Hijau (LH) }\end{array}$ & $\begin{array}{l}> \\
\mathrm{km}\end{array}$ & $\begin{array}{l}(1000- \\
1500) \mathrm{km}\end{array}$ & $\begin{array}{l}(500- \\
1000) \mathrm{km}\end{array}$ & $\begin{array}{l}(50-500) \\
k m\end{array}$ & $<50 \mathrm{~m}$ \\
\hline 6 & Litologi (L) & $\begin{array}{l}\text { Batuan } \\
\text { Batuan } \\
\text { beku, } \\
\text { sedimen } \\
\text { metamo } \\
\text { rf, } \\
\text { kompak }\end{array}$ & $\begin{array}{l}\text { Batuan } \\
\text { beku, } \\
\text { sedimen, } \\
\text { berbutir } \\
\text { halus, } \\
\text { kompak }\end{array}$ & $\begin{array}{l}\text { Sedimen } \\
\text { Gravel } \\
\text { dan Pasir } \\
\text { Kasar } \\
\text { agak } \\
\text { Kompak }\end{array}$ & $\begin{array}{l}\text { Pasir, } \\
\text { Lanau, } \\
\text { lempng } \\
\text { agak } \\
\text { Kompak }\end{array}$ & $\begin{array}{l}\text { Pasir, } \\
\text { lanau, } \\
\text { Lempung } \\
\text { Lumpur, } \\
\text { Lepas }\end{array}$ \\
\hline
\end{tabular}




\begin{tabular}{|c|c|c|c|c|c|c|}
\hline & & dan & dan lunak & & & \\
\hline 7 & $\begin{array}{l}\text { Penggunaan } \\
\text { lahan (PL) }\end{array}$ & $\begin{array}{l}\text { Tegalan } \\
\text {,Hutan } \\
\text { Bakau, } \\
\text { tanah } \\
\text { Kosong } \\
\text { dan } \\
\text { Rawa }\end{array}$ & $\begin{array}{l}\text { Daerah } \\
\text { Wisata } \\
\text { Domestik } \\
\text {,Tambak } \\
\text { trdisional, } \\
\text { Perkebun } \\
\text { an }\end{array}$ & $\begin{array}{l}\text { Persawa } \\
\text { han dan } \\
\text { tambak } \\
\text { Intensif }\end{array}$ & $\begin{array}{l}\text { Pemuki } \\
\text { man, } \\
\text { Pelabuh } \\
\text { an, } \\
\text { Perkant } \\
\text { oran, } \\
\text { Sekolah } \\
\text { dan } \\
\text { Jalan } \\
\text { Propinsi }\end{array}$ & $\begin{array}{l}\text { Cagar } \\
\text { Budaya, } \\
\text { Daerah } \\
\text { Wisata } \\
\text { Berdevisa, } \\
\text { Industri, } \\
\text { Jalan } \\
\text { Negara dan } \\
\text { Fasiltas } \\
\text { Pertahanan } \\
\text { Negara }\end{array}$ \\
\hline 8 & $\begin{array}{l}\text { Kemiringan } \\
\text { pantai }(\beta)\end{array}$ & 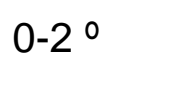 & $2-5^{\circ}$ & 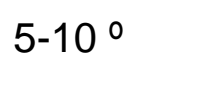 & $10-15^{\circ}$ & $>15^{\circ}$ \\
\hline
\end{tabular}

\section{HASIL DAN PEMBAHASAN}

Sumberdaya wilayah pesisir Kota Bengkulu terdiri dari ekosistem hutan pantai (termasuk ekosistem hutan mangrove), ekosistem perairan laut, sumberdaya perikanan, potensi jasa-jasa pariwisata dan pulau kecil (Pulau Tikus). Ekosistem hutan mangrove tidak begitu banyak, dan letaknya terpencar-pencar, tidak pada suatu hamparan yang luas. Ekosistem hutan mangrove terdapat di Kawasan TWA (Taman Wisata Alam) Pantai Panjang, Dusun Kandang, Pulau Baai, Padang Serai dan Sungai Jenggalu. Untuk saat ini, keberadaan ekosistem hutan mangrove di Kota Bengkulu tetap mempunyai fungsi dan peranan yang besar baik bagi masyarakat maupun sebagai daerah penyangga.

Kondisi ekosistem hutan mangrove ini sendiri sudah mengalamai degradasi, karena sudah dimanfaatkan untuk berbagai kepentingan seperti pertambakan, pemukiman dan perluasan wilayah Kota Bengkulu. Menurut Dirjen P3K DKP (2004), ekosistem mangrove potensial mendapat tekanan dari kegiatan manusia dan pembangunan, terlebih lagi pesisir merupakan wilayah dengan tingkat aktivitas perekonomian tinggi. Kustanti (2011) mengemukakan, bahwa konversi hutan mangrove untuk budidaya perikanan, terutama untuk tambak udang windu dan tambak ikan telah menyebabkan terdegradasinya hutan mangrove yang subur dalam skala yang cukup luas.

Hutan pantai di wilayah pesisir Kota Bengkulu, sebagian besar sudah banyak berubah fungsinya dari ekosistem penyangga (buffer region) atau sebagai jalur hijau, menjadi pemukiman dan pengembangan wilayah pariwisata serta pembangunan berbagai fasilitas umum dan pemerintah. Kota Bengkulu memiliki areal TWA (Taman Wisata Alam) Pantai Panjang Pulau Baai mulai dari Muara Sungai Jenggalu sampai ke Bangkahan Ujung, dengan luas \pm 967 hektar dan saat ini kondisinya rusak parah akibat perambah liar dan tumpang tindih dengan kebijakan pembangunan kota. Menurut Juralis (2008), beberapa spesies burung yang sedikit 
ditemukan diduga karena kawasan TWA Pantai Panjang Kota Bengkulu sudah terganggu yang disebabkan kegiatan masyarakat sekitar yang menggunakan TWA untuk lahan pertanian, perkebunan, pemukiman dan pembukaan jalan.

Hasil survey menunjukkan terdapat 14 titik lokasi kerusakan wilayah pesisir Kota Bengkulu, dengan 4 jenis kerusakan yaitu kerusakan hutan pantai (KHP), kerusakan pantai (KP), kerusakan muara sungai (KMS), dan kerusakan hutan mangrove (KHM).

Tabel 2. Lokasi, jenis, penyebab dan dampak kerusakan daerah pesisir Kota Bengkulu

\begin{tabular}{|c|c|c|c|c|}
\hline No. & Lokasi & $\begin{array}{l}\text { Jenis } \\
\text { Kerusakan }\end{array}$ & $\begin{array}{l}\text { Penyebab } \\
\text { Kerusakan }\end{array}$ & $\begin{array}{l}\text { Dampak/akibat } \\
\text { kerusakan }\end{array}$ \\
\hline 1 & $\begin{array}{l}\text { Pantai } \\
\text { Sumber } \\
\text { Jaya }\end{array}$ & $\mathrm{KHM}$ & $\begin{array}{l}\text { Alih fungsi lahan } \\
\text { menjadi } \\
\text { pemukiman, } \\
\text { tambak dan } \\
\text { ladang dan } \\
\text { perambahan } \\
\text { hutan mangrove }\end{array}$ & $\begin{array}{l}\text { Degradasi luas } \\
\text { hutan mangrove, } \\
\text { berkurangnya hasil } \\
\text { tangkapan nelayan }\end{array}$ \\
\hline 2 & $\begin{array}{l}\text { Pantai } \\
\text { Samudera } \\
\text { Ujung }\end{array}$ & $\begin{array}{l}\mathrm{KHP} \\
\mathrm{KP}\end{array}$ & $\begin{array}{l}\text { Alih fungsi lahan } \\
\text { menjadi tempat } \\
\text { penumpukkan } \\
\text { pasir hasil galian } \\
\text { alur pelabuhan, } \\
\text { sedimentasi }\end{array}$ & $\begin{array}{lr}\text { Degradasi } & \text { luas } \\
\text { hutan } & \text { pantai, } \\
\text { degradasi } & \text { lebar } \\
\text { sabuk } & \text { hijau, } \\
\text { perubahan morfologi } & \text { pantai, } \\
\text { pendangkalan } & \end{array}$ \\
\hline 3 & $\begin{array}{l}\text { Pantai } \\
\text { Teluk } \\
\text { Sepang }\end{array}$ & $\begin{array}{l}\mathrm{KHP} \\
\mathrm{KP}\end{array}$ & $\begin{array}{l}\text { Abrasi, alih fungsi } \\
\text { lahan }\end{array}$ & $\begin{array}{l}\text { Perubahan morfologi } \\
\text { pantai, Degradasi } \\
\text { luas hutan pantai, } \\
\text { Degradasi lebar } \\
\text { sabuk hijau }\end{array}$ \\
\hline 4 & $\begin{array}{l}\text { Pantai } \\
\text { Terminal } \\
\text { Sungai } \\
\text { Hitam }\end{array}$ & $\begin{array}{l}\mathrm{KHP} \\
\mathrm{KP}\end{array}$ & $\begin{array}{l}\text { Alih fungsi lahan } \\
\text { untuk } \\
\text { pemukiman, } \\
\text { pencemaran } \\
\text { sampah }\end{array}$ & $\begin{array}{lr}\text { Degradasi } & \text { luas } \\
\text { hutan } & \text { pantai, } \\
\text { Degradasi } & \text { lebar } \\
\text { sabuk hijau } & \\
\text { Rusaknya } & \text { estetika } \\
\text { pantai } & \end{array}$ \\
\hline 5 & $\begin{array}{l}\text { Muara } \\
\text { Sungai } \\
\text { Bengkulu }\end{array}$ & $\begin{array}{l}\text { KMS } \\
\mathrm{KP}\end{array}$ & $\begin{array}{l}\text { Pencemaran } \\
\text { sampah dan batu } \\
\text { bara, abrasi. } \\
\text { sedimentasi }\end{array}$ & $\begin{array}{l}\text { Rusaknya estetika } \\
\text { pantai, perubahan } \\
\text { morfologi pantai, } \\
\text { pendangkalan } \\
\text { muara sungai, } \\
\text { rusaknya jalan raya }\end{array}$ \\
\hline 6 & $\begin{array}{l}\text { Pantai } \\
\text { Jembatan }\end{array}$ & $\begin{array}{l}\mathrm{KHP} \\
\mathrm{KP}\end{array}$ & $\begin{array}{l}\text { Alih fungsi lahan } \\
\text { menjadi tempat }\end{array}$ & $\begin{array}{l}\text { Rusaknya estetika } \\
\text { pantai, Degradasi }\end{array}$ \\
\hline
\end{tabular}


Sungai

Bengkulu

7

$\begin{array}{ll}\text { Pantai } & \text { KHP } \\ \text { Pasar } & \text { KP } \\ \text { Bengkulu } & \end{array}$

8

Pantai Jakat

KHP
KP

9

$\begin{array}{ll}\text { Pantai } & \text { KHP } \\ \text { Pondok } & \text { KP } \\ \text { Besi } & \end{array}$

10

Pantai KHP

Malabero

$\begin{array}{ll}\text { Pantai } & \text { KHP } \\ \text { Sumur } & \text { KP } \\ \text { Meleleh } & \end{array}$

wisata dan usaha

warung, pemukiman, dan pencemaran sampah, sedimentasi

Alih fungsi lahan Rusaknya estetika menjadi tempat wisata dan usaha warung, pemukiman, dan pencemaran sampah, sedimentasi

Alih fungsi lahan menjadi tempat wisata dan usaha warung,

pemukiman, dan pencemaran sampah, sedimentasi

Alih fungsi lahan menjadi tempat wisata dan usaha warung, pemukiman, dan pencemaran sampah, sedimentasi

Alih fungsi lahan menjadi tempat wisata dan usaha warung, pemukiman, dan abrasi

Alih fungsi lahan menjadi tempat wisata dan usaha warung, pemukiman, dan sedimentasi luas hutan pantai, Degradasi lebar sabuk hijau, pendangkalan dan penambahan lebar pantai.

pantai, Degradasi luas hutan pantai, Degradasi lebar sabuk hijau, pendangkalan dan penambahan lebar pantai

Rusaknya estetika pantai, Degradasi luas hutan pantai, Degradasi lebar sabuk hijau, pendangkalan dan penambahan lebar pantai

Rusaknya estetika pantai, Degradasi luas hutan pantai, Degradasi lebar sabuk hijau, pendangkalan dan penambahan lebar pantai

Degradasi luas

hutan pantai,

Degradasi lebar sabuk hijau, perubahan morfologi pantai, berkurangnya lebar pantai

Degradasi luas

hutan pantai,

Degradasi lebar sabuk hijau, pendangkalan, perubahan morfologi pantai dan penambahan lebar 


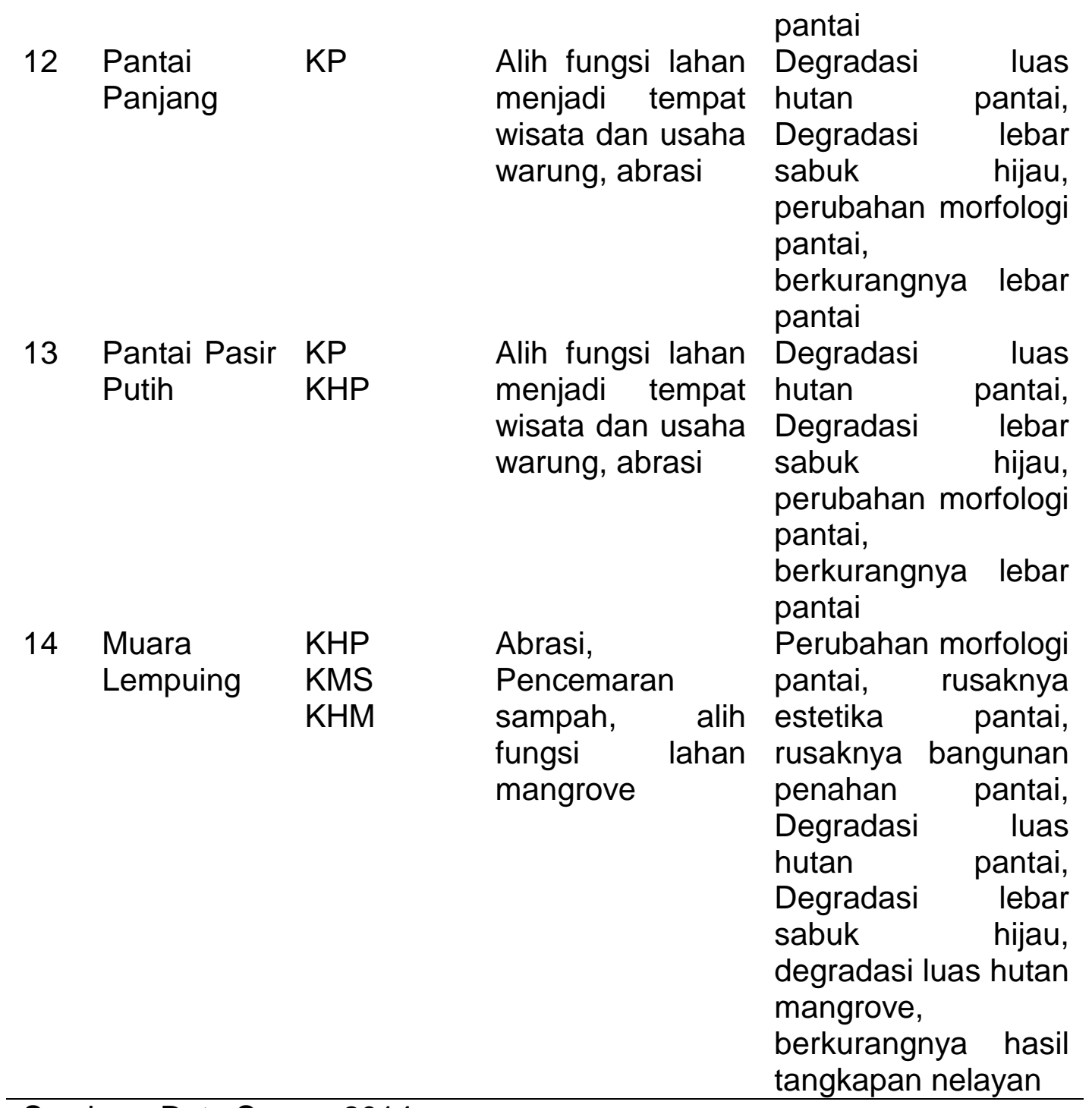

Sumber : Data Survey 2014

Kerusakan pantai dan kerusakan hutan pantai yang disebabkan oleh abrasi, sedimentasi dan alih fungsi lahan merupakan permasalahan utama yang dihadapi oleh daerah pesisir Provinsi Bengkulu. Alih fungsi lahan menjadi tempat wisata, tempat usaha dan pemukiman merupakan resiko yang harus bisa dihadapi oleh daerah pesisir yang menjadi pusat pariwisata. Namun, apabila resiko yang ada dapat dikelola dengan baik, maka kerusakan daerah pesisir dapat diminimalisir. Sebagai yang dikemukan oleh Tuheteru dan Mahfudz (2012) bahwa aktivitas pariwisata dan rekreasi dapat berdampak negatif terhadap kelestarian ekosistem pantai. Pembangunan sarana prasarana pariwisata seperti pembangunan hotel, resort, pembangunan dermaga dan sarana lalu lintas turut berkontribusi terhadap menurunnya stabilitas fisik dan meningkatnya mobilitas pasir.

Untuk permasalahan tersebut alternatif penanggulangannya yaitu (1) pembuatan bangunan pantai untuk mencegah abrasi (2) Penataan lokasi 
tempat usaha agar tidak merusak/menggangu hutan pantai atau sabuk hijau (3). Penyusunan manajemen pengelolaan sampah. Namun untuk lebih detail, alternatif penanggulangan atau rehabilitasi untuk masingmasing lokasi disajikan pada Tabel 3.

Tabel 3. Lokasi, Permasalahan, Indeks Kerentanan Pantai (IKP) dan alternatif penanggulangan kerusakan daerah pesisir Kota Bengkulu

\begin{tabular}{|c|c|c|c|c|}
\hline No. & Lokasi & $\begin{array}{l}\text { Permasalahan } \\
\text { Yang dihadapi }\end{array}$ & IKP & $\begin{array}{l}\text { Alternatif } \\
\text { Penanggulangan/Rehabilitasi }\end{array}$ \\
\hline 1 & $\begin{array}{l}\text { Pantai } \\
\text { Sumber } \\
\text { Jaya }\end{array}$ & $\begin{array}{l}\text { Alih fungsi } \\
\text { lahan untuki } \\
\text { pemukiman, } \\
\text { tambak dan } \\
\text { ladang, } \\
\text { perambahan } \\
\text { hutan } \\
\text { mangrove }\end{array}$ & 26,8 & $\begin{array}{l}\text { Penguatan regulasi } \\
\text { pemanfaatan lahan pantai } \\
\text { melalui perda, mengembalikan } \\
\text { fungsi dan menanam vegetasi } \\
\text { mangrove }\end{array}$ \\
\hline 2 & $\begin{array}{l}\text { Pantai } \\
\text { Samudera } \\
\text { Ujung }\end{array}$ & $\begin{array}{l}\text { Alih fungsi } \\
\text { lahan untuk } \\
\text { penumpukkan } \\
\text { pasir galian alur } \\
\text { pelabuhan, } \\
\text { pendangkalan, } \\
\text { Degradasi luas } \\
\text { hutan pantai, } \\
\text { lebar sabuk } \\
\text { hijau }\end{array}$ & 19 & $\begin{array}{l}\text { Penguatan regulasi } \\
\text { pemanfaatan lahan pantai } \\
\text { melalui perda, Mengembalikan } \\
\text { fungsi dan menanam vegetasi } \\
\text { pantai, pemindahan pasir } \\
\text { galian ke daerah pesisir yang } \\
\text { mengalami abrasi, } \\
\text { pembangunan penahan pantai } \\
\text { (jetty) }\end{array}$ \\
\hline 3 & $\begin{array}{l}\text { Pantai } \\
\text { Teluk } \\
\text { Sepang }\end{array}$ & $\begin{array}{l}\text { Abrasi, alih } \\
\text { fungsi lahan, } \\
\text { Perubahan } \\
\text { morfologi } \\
\text { pantai, } \\
\text { degradasi luas } \\
\text { hutan pantai, } \\
\text { degradasi lebar } \\
\text { sabuk hijau }\end{array}$ & 13,4 & $\begin{array}{l}\text { Pembangunan penahan pantai } \\
\text { (revetment), penguatan } \\
\text { regulasi pemanfaatan lahan } \\
\text { pantai melalui perda, perdes, } \\
\text { atau kearifan lokal, } \\
\text { Mengembalikan } \\
\text { vegetasi pantai, replant } \\
\text { vegetasi pantai, }\end{array}$ \\
\hline 4 & $\begin{array}{l}\text { Pantai } \\
\text { Terminal } \\
\text { Sungai } \\
\text { Hitam }\end{array}$ & $\begin{array}{l}\text { Alih fungsi } \\
\text { lahan untuk } \\
\text { pemukiman, } \\
\text { pencemaran } \\
\text { sampah, } \\
\text { degradasi luas } \\
\text { hutan pantai, } \\
\text { degradasi lebar } \\
\text { sabuk hijau }\end{array}$ & 17,9 & $\begin{array}{l}\text { Penguatan regulasi } \\
\text { pemanfaatan lahan pantai } \\
\text { melalui perda, Mengembalikan } \\
\text { fungsi vegetasi pantai, replant } \\
\text { vegetasi pantai, bersih pantai, } \\
\text { penyusunan manajemen } \\
\text { pengelolaan sampah }\end{array}$ \\
\hline
\end{tabular}




\begin{tabular}{|c|c|}
\hline Muara & Pencemaran \\
\hline Sungai & sampah dan \\
\hline Bengkulu & batu bara, \\
\hline \multirow{10}{*}{$\begin{array}{l}\text { Pantai } \\
\text { Jembatan } \\
\text { Sungai } \\
\text { Bengkulu }\end{array}$} & Sedimentasi \\
\hline & Alih fungsi \\
\hline & lahan \\
\hline & tempat wisata, \\
\hline & warung, \\
\hline & pencemaran \\
\hline & sampah, \\
\hline & $\begin{array}{l}\text { sedimentasi; } \\
\text { degradasi luas }\end{array}$ \\
\hline & hutan pantai \\
\hline & $\begin{array}{l}\text { dan lebar sabuk } \\
\text { hijau }\end{array}$ \\
\hline
\end{tabular}

7 Pantai Alih fungsi

Pasar lahan untuk

Bengkulu tempat wisata, warung,

pemukiman;

pencemaran

sampah,

sedimentasi, degradasi luas hutan pantai dan lebar sabuk hijau

8 Pantai Jakat
Alih fungsi lahan untuk tempat wisata dan usaha warung, pemukiman, dan pencemaran sampah, sedimentasi, degradasi luas hutan pantai dan lebar sabuk hijau

Alih fungsi lahan untuk tempat wisata dan usaha
17,9 Bersih pantai, penyusunan manajemen pengelolaan sampah, pengerukan, pembangunan penahan pantai mulut muara (revetment).

12,6 Penguatan regulasi pemanfaatan lahan pantai melalui perda, Bersih pantai, penyusunan manajemen pengelolaan sampah, Mengembalikan fungsi vegetasi pantai, replant vegetasi pantai
12,6 Penguatan regulasi pemanfaatan lahan pantai melalui perda, Bersih pantai, penyusunan manajemen pengelolaan sampah, Mengembalikan fungsi vegetasi pantai, replant vegetasi pantai,
17,9 Penguatan regulasi pemanfaatan lahan pantai melalui perda, Bersih pantai, penyusunan manajemen pengelolaan sampah, Mengembalikan fungsi vegetasi pantai, replant vegetasi pantai

8,9 Penguatan regulasi pemanfaatan lahan pantai melalui perda, Bersih pantai, penyusunan manajemen 
10 Pantai Malabero

11 Pantai Sumur Meleleh

$$
\begin{aligned}
& \text { Pantai } \\
& \text { Panjang }
\end{aligned}
$$

13 Pantai

Pasir

Putih

warung,
pemukiman,
dan
pencemaran
sampah,
sedimentasi
menggangu
fasilitas tambat
TPI pondok
besi, degradasi
luas hutan
pantai dan
lebar sabuk
hijau

Alih fungsi lahan menjadi tempat wisata dan usaha warung, pemukiman, dan abrasi, degradasi luas hutan pantai dan lebar sabuk hijau

Alih fungsi lahan menjadi tempat wisata dan usaha warung, pemukiman, dan sedimentasi, degradasi luas hutan pantai dan lebar sabuk hijau

Alih fungsi lahan menjadi tempat wisata dan usaha warung, abrasi
Alih fungsi lahan menjadi tempat wisata dan usaha warung, abrasi
34,6 Penguatan regulasi pemanfaatan lahan pantai melalui perda, pembuatan bangunan penahan pantai (revetment).

pengelolaan sampah dan pengerukan dan pembuatan bangunan penahan pantai agara sedimen tidak kembali lagi, Mengembalikan fungsi vegetasi pantai, replant vegetasi pantai
17,9 Penguatan regulasi pemanfaatan lahan pantai melalui perda, bangunan penahan pantai sudah ada, Mengembalikan fungsi vegetasi pantai, replant vegetasi pantai

19,6 Penguatan regulasi pemanfaatan lahan pantai melalui perda, ada bangunan penahan pantai 


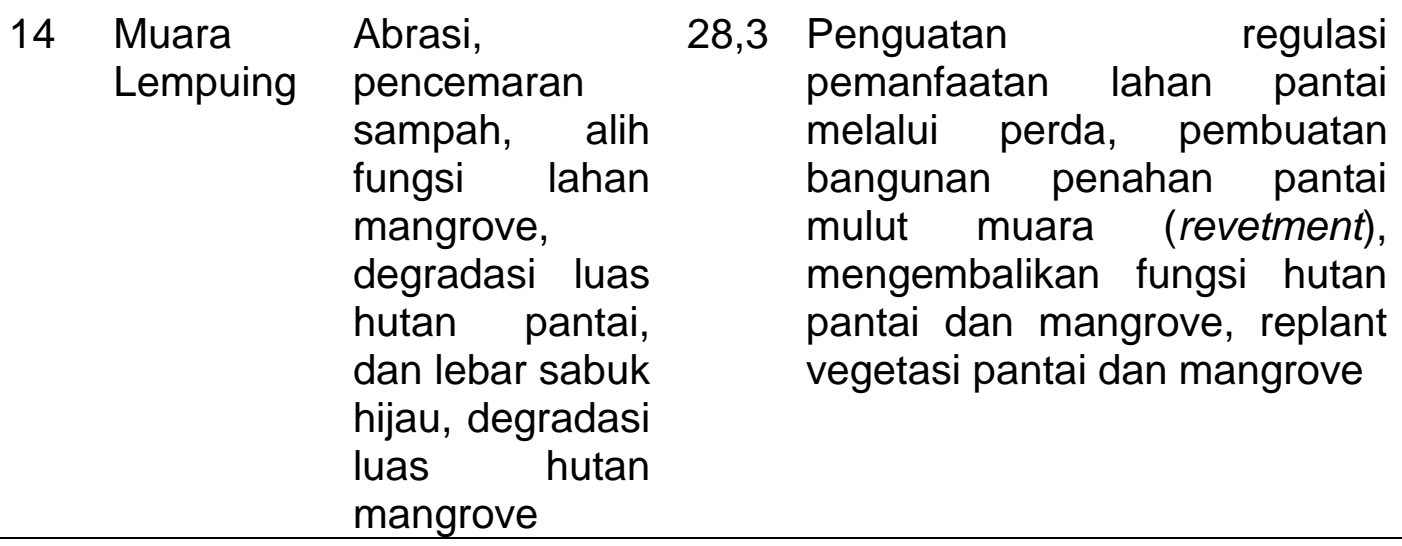

Sumber : Analisis Data Survey 2014

Pada Tabel 3 dapat diketahui bahwa 11 lokasi dari 14 lokasi titik kerusakan wilayah pesisir di Kota Bengkulu, permasalahannya berkaitan dengan alih fungsi lahan menjadi pemukiman, warung, tambak dan tempat wisata. Permasalahan lainnya adalah abrasi, pencemaran (sampah dan batubara), degradasi hutan pantai dan berkurangnya sabuk hijau. Kondisi ini dapat saja dipengaruhi oleh pemenuhan kebutuhan ekonomi karena adanya pertumbuhan penduduk yang cepat. Seperti pendapat Effendy (2009), bahwa dengan pertumbuhan penduduk yang tinggi dan pesatnya kegiatan pembangunan di pesisir bagi berbagai peruntukan (industri, pelabuhan, tambak, pemukiman), maka tekanan ekologis terhadap ekosisitem pesisir semakin meningkat pula.

Dari hasil perhitungan Nilai IKP, kerusakan wilayah pesisir yan paling parah terdapat di Lokasi Pantai Pasir Putih (IKP $=34,6)$, sedangkan kerusakan paling ringan ada di lokasi Pantai Pondok Besi (IKP = 8,9).

Alternatif penanggulangan kerusakan wilayah pesisir di Kota Bengkulu secara umum memerlukan adanya penguatan regulasi pemanfaatan lahan melalui peraturan daerah. Hal ini mungkin masih lemahnya pengaturan tata ruang wilayah pesisir. Penelitian Salim et al (2011) menyimpulkan, bahwa pemanfaatan ruang yang tidak terkendali karena zonasi ruang yang tidak jelas, sementara masyarakat dalam memanfaatkan lahan hanya didasarkan pada kepemilikan tanah yang dimiliki secara turun temurun. Kondisi ini makin menimbulkan dampak pemanfaatan ruang yang semakin tidak terkendali. Lasabuda (2013) juga menyatakan bahwa beberapa kegiatan yang diduga menyebabkan erosi pantai antara lain : pengambilan pasir untuk reklamasi, pembangunan pelabuhan/jetty/marina, pembangunan hotel. Hal ini terjadi karena perencanaan dan pengembangan wilayah pesisir yang tidak tepat.

Abrasi di wilayah pesisir pantai Kota Bengkulu juga mengancam pemukiman, bangunan fasilitas umum dan obyek-obyek wisata, seperti wisata pantai. Dari 14 lokasi kerusakan wilayah pesisir di Kota Bengkulu terjadi kasus sedimentasi di pantai Pondok Besi yang menyebabkan PPI Pondok Besi tidak berfungsi. Penelitian Dewi (2013) menjelaskan, bahwa adanya bangunan jetty pada kawasan Tapak Paderi menyebabkan gelombang yang menghampiri ujung jetty mengalami proses difraksi 
sehingga terjadi pembelokan sedimen masuk kedalam alur yang menyebabkan pendangkalan pada alur pelabuhan dan terus dilanjutkan hungga mencapai dermaga PPI Pondok Besi sehingga terjadi pendangkalan.

Untuk mempermudah dalam hal identifikasi data-data lokasi, jenis dan nilai IKP dari masing-masing lokasi kami tampilkan dalam Gambar 1. berikut ini.

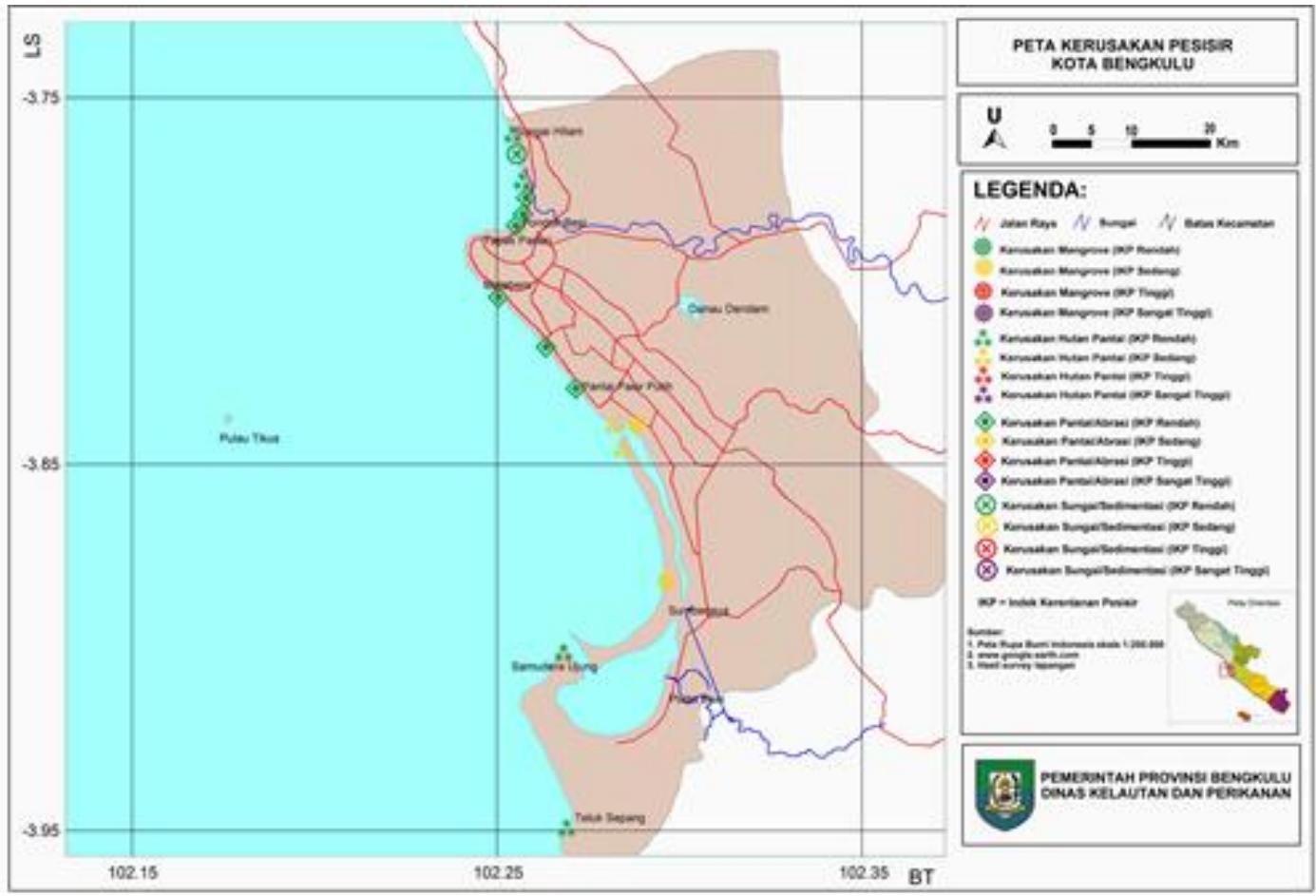

Gambar 1. Peta sebaran lokasi, jenis dan IKP kerusakan daerah pesisir Kota Bengkulu (Sumber: Analisis data survey 2014)

\section{KESIMPULAN}

Secara umum wilayah pesisir Kota Bengkulu, Provinsi Bengkulu sudah mengalami degradasi. Ada 4 jenis kerusakan wilayah pesisir Kota Bengkulu yaitu kerusakan hutan pantai, kerusakan pantai, kerusakan muara sungai dan kerusakan hutan mangrove. Ada 14 lokasi titik kerusakan wilayah pesisir di Kota Bengkulu. Dari 14 lokasi tersebut ada 11 lokasi yang kerusakannya berkaitan dengan alih fungsi lahan menjadi pemukiman, warung, tambak dan tempat wisata. Permasalahan lainnya adalah abrasi, pencemaran (sampah dan batubara), degradasi hutan pantai dan berkurangnya sabuk hijau. Kerusakan wilayah pesisir yan paling parah terdapat di Lokasi Pantai Pasir Putih (IKP $=34,6)$, sedangkan kerusakan paling ringan ada di lokasi Pantai Pondok Besi (IKP = 8,9). Alternatif penanggulangan kerusakan wilayah pesisir di Kota Bengkulu secara umum memerlukan adanya penguatan regulasi pemanfaatan lahan melalui peraturan daerah. 


\section{DAFTAR PUSTAKA}

Adisasmita, R., 2008. Ekonomi Archipelago. Cetakan Pertama. Graha Ilmu, Yogyakarta. 230 hal.

Arianto, W., Zamdial Ta'alidin, Rustama Saepudin dan Dede Hartono, 2013. Valuasi Ekonomi Sumberdaya Hayati Pesisir Dan Laut Kawasan Pulau Enggano. Laporan Akhir Hibah Kompetisi Bantuan Operasional Perguruan Tinggi (BOPT) 2013. Universitas Bengkulu 2013. 87 hal.

Bappeda Kota Bengkulu, 2013. Rencana Strategis Bappeda Kota Bengkulu 2013-2018. Pemerintahan Kota Bengkulu.

Boruff, B. J., Emrich, C., \& Cutter, S. L., 2005. Erosion hazard vulnerability of US coastal counties. Journal of Coastal Research, Vol. 21 No. 5 ; 932-942.

BPS Kota Bengkulu, 2014. Kota Bengkulu Dalam Angka 2014. BPS Kota Bengkulu.

Dewi, T. Andam, 2013. Kajian Karakteristik Gelombang dan Arus Dalam Kaitannya dengan Proses Pendangkalan PPI Pondok Besi Kota Bengkulu. Skripsi. Program Studi IImu kelautan, Jurusan Peternakan, fakultas Pertanian Universitas Bengkulu. 30 hal.

Dirjen P3K DKP RI, 2004. Pedoman Pengelolaan Ekosistem Mangrove. Direktorat Bina Pesisir, Dirjen P3K Departemen Kelautan dan Perikanan RI. 123 hal.

Effendy, M., 2009. Pengelolaan Wilayah Pesisir Secara Terpadu: Solusi Pemanfaatan Ruang, Pemanfaatan Sumberdaya Dan Pemanfaatan Kapasitas Asimilasi Wilayah Pesisir Yang Optimal Dan Berkelanjutan. Jurnal Kelautan, Vol. 2 No. 1; 81-86.

Fauzi, Y., Boko Susilo, dan Zwlfta Memi Mayasad, 2009. Analisis Kesesuaian Lahail Wii.Ayah Pesisir Kota Bengkulu Melalui Perancangail Model Spasial Dan Sistem Informasi Geografis (Sig). Jurnal Geografi Universitas Surakarta. Forum Geografi, Vol. 23, No. 2, Desernber'2009: 101-111.

Jarulis, 2008. Burung-Burung di Kawasan Taman WIsata Alam Pantai Panjang Kota Bengkulu. Jurnal Exacta Vol. VI No. 1 Juni 2008; 142-148. 
Kustanti, A., 2011. Manajemen Hutan Mangrove. Penyunting : Prof. Dr. Ir. Cecep Kusmana, MS. Penerbit IPB Press. 248 hal.

Lasabuda, R., 2013. Pembangunan Wilayah Pesisir Dan Lautan Dalam Perspektif Negara Kepulauan Republik Indonesia. Tinjauan Teoritis. Jurnal IImiah Platax Vol. I-2, Januari 2013; 92-101.

Purwanto S.K., S., 2012. Statistika untuk Ekonomi dan Keuangan Modern. Jakarta: Salemba Empat.

Salim, A. Rasid, Hartuti Purnaweni, Wahyu Hidayat, 2011. Kajian Pemanfaatan Ruang Kawasan Pesisir Kabupaten Bone Bolango Yang Berwawasan Lingkungan (Studi Kasus Desa Botubarani Dan Desa Huangobotu). Jurnal IImu Lingkungan Vol.9, No. 1, April 2011; 39-46.

Suparmi, Ch., 2014. Konsep Dasar Statistik. Modul 1. Universitas Terbuka. 55 hal.

Tuheteru, FD dan Mahfudz. 2012. Ekologi, Manfaat \& Rehabilitasi, Hutan Pantai Indonesia. Balai Penelitian Kehutanan Manado. Manado, Indonesia. 178 hal.

Wahyudi, Teguh Hariyanto dan Suntoyo, 2009. Analisa Kerentanan Pantai di Wilayah Pesisir Pantai Utara Jawa Timur. SENTA. 9 hal. 